\title{
Adsorbents for glyphosate removal in contaminated waters: a review
}

Autores: Hercules Abie Pereira, Paola Rosiane Teixeira Hernandes, Matias Schadeck Netto, Gabriel Diogo Reske, Viviane Vieceli, Luis Felipe Silva Oliveira \& Guilherme Luiz Dotto

\begin{abstract}
Glyphosate is an herbicide used to control weeds and optimize agricultural production. However, since glyphosate is an emerging pollutant claimed to be potentially carcinogenic, glyphosate pollution of soils and water is a health issue. There is therefore a need for advanced techniques to remove glyphosate from the environment. Here, we review glyphosate properties and materials for glyphosate adsorption such as biochar and graphene, which display high glyphosate adsorption capacities.
\end{abstract}

Keywords: Environmental pollution, Herbicide, Adsorbent materials, Glyphosate removal, Adsorption

DOI: https://doi.org/10.1007/s10311-020-01108-4

URL: https://link.springer.com/article/10.1007/s10311-020-01108-4 